\title{
COMPARTILHANDO EXPERIÊNCIAS NA CONSTRUÇÃO DE SOLUÇÕES PARA UMA INDÚSTRIA 4.0.
}

\author{
RIO DE JANEIRO/RJ AGOSTO/2018 \\ Paulo Robson Coelho Sampaio ～- SENAI CETIQT - prsampaio@cetiqt.senai.br \\ Tipo: Relato de Experiência Inovadora (EI) \\ Categoria: Conteúdos e Habilidades
}

Setor Educacional: EDUCAÇÃo MÉDIA E TECNOLÓGICA, EDUCAÇÃO CONTINUADA EM GERAL

\section{RESUMO}

Os desafios de implementação de soluções para a Indústria 4.0 no Brasil não se limitam às questões tecnológicas, mas tem forte apelo junto à qualificação da mão de obra em nível nacional. A realização de uma experiência de aprendizagem de gestores do programa Master Business Innovation em Confecção 4.0 apresenta realidades contrastantes entre o público que materializa a produção nacional desse setor industrial vis-a-vis às demandas por competências transversais.

Buscando uma apropriação da classe empresarial acerca das formações específicas necessárias a um projeto de industrialização baseado no desenvolvimento de pessoas, o referido $\mathrm{MBI}$ traz como problema a elaboração de projetos que contemplem realidade socioeconomicas e culturais alinhadas com a sustentabilidade da indústria. Além disso, insere questões de tecnologia avançada na pauta da educação profissional e tecnológica.

Palavras-chave: PBL; SENAI; MBI; Indústria 4.0

\section{AGRADECIMENTOS}

AO SENAI CETIQT POR COMPARTILHAR ESSA EXPERIÊNCIA DE EDUCAÇÃO E INOVAÇÃO. 


\section{INTRODUÇÃO}

Os desafios de implementação de soluções para a Indústria 4.0 no Brasil não se limitam às questões tecnológicas, mas têm forte apelo junto à qualificação da mão de obra em nível nacional. Isso foi evidenciado em estudos da Confederação Nacional da Indústria CNI (2006 p.24) que identificaram, entre as dimensões prioritárias para 0 desenvolvimento da Indústria 4.0, a formação específica de recursos humanos trazendo uma perspectiva multidisciplinar e associada à parâmetros de conectividade e compartilhamento.

Nesse sentido, a experimentação do SENAI CETIQT na implementação de um programa de Pós-graduação Master Business Innovation em Confecção 4.0 busca mostrar uma saída articulada entre as a classe empresarial e trabalhadora a fim de criar novos espaços de consciência em torno de um projeto inovador de desenvolvimento industrial.

Para tanto, um blended de metodologias de Educação à distância e modalidades de ensino (à distância e presencial) é proposto oportunizando possíveis ajustes voltados, em um primeiro momento às necessidades corporativas das indústrias, como Pesquisa, Inovação e Desenvolvimento e, a posteriori, a identificação de formas para o desenvolvimento de pessoas no setor industrial. Em um movimento inicial, a formação de gestores quanto à indústria 4.0 é apresentada em um Problem Based Learning (NIU; STANFORD, 2018) sugerindo a elaboração de projetos com contexto socioeconômicos condizentes com a realidade brasileira em uma agenda de desenvolvimento proposta como tema prioritário, segundo a CNI (2016 a, p. 156). Na sequência, a construção de uma metodologia própria dá a exclusividade do programa $\mathrm{MBI}$ que será discutida nesse trabalho.

Com isso, o objetivo desse artigo é identificar as dinâmicas propostas para ensinoaprendizagem de um tema estratégico para o desenvolvimento socioeconômico nacional, sob a luz de conteúdos que refletem uma consciência da classe empresarial e projetam programas de qualificação para os trabalhadores da indústria têxtil e de confecção.

\section{REFERENCIAL TEÓRICO}

A Educação Profissional e Tecnológica é uma educação para o trabalho e historicamente define um ponto de tensão entre classes economicamente antagônicas. No entanto, com as elaborações legalizadas dos currículos nacionais (BRASIL, 1996), o 
que antes era velado como uma prática senhorial de influência nas políticas educacionais, passa a ser uma estratégia baseada nas necessidades patronais/empresariais/corporativas.

A categoria princípio educativo do trabalho, que supõe a compreensão dos processos de formação humana, e portanto, superestruturais, a partir das bases materiais de produção da existência (infra estruturais), constitui, decorrente que é da centralidade da categoria trabalho (...) O princípio educativo define os processos de formação dos intelectuais que irão desempenhar as diferentes funções no sistema social e produtivo, e sua apreensão só será possível a partir do estudo das bases materiais que Ihe dão origem. (KUENZER E GRABOWSK, 2016, p. 24)

Para além dessa discussão, a popularização das Tecnologias de Informação e Comunicação trazem um reposicionamento de classes quanto à intelectualização do trabalho e da utilização de métodos de ensino-aprendizagem com vistas ao desenvolvimento de uma força de trabalho não apenas mecanizada, mas com um aporte de criatividade cada vez maior.

\footnotetext{
A força criativa desenvolve-se, principalmente, por meio de estratégias de problematização da realidade e dos conteúdos escolares, suscitando a busca por ferramentas, teóricas e práticas, capazes de auxiliar os indivíduos no enfrentamento de suas tarefas cotidianas e históricas. (ARAÚJO E FRIGOTTO, 2015, p. 74)
}

Com isso, temas com a Indústria 4.0 reforçam a necessidade de compreender a pluralidade de métodos que facilitem a formação profissional, mas também garantam a identificação da consciência de classe empresarial em alcançar seus objetivos. Nesse sentido:

Tendo por base a Visão 2030 (da indústria), os elementos estratégicos, as tendências, as tecnologias ubíquas e as novas tecnologias para Confecção 4.0 que deverão orientar a adoção de princípios de manufatura avançada na indústria têxtil e de confecção brasileira(..)diferenciam-se as bases institucionais, as capacidades instaladas e as competências humanas(...) em cada uma das ênfases estratégica: Confecção, Design Novas Fibras e Novos Canais. (BRUNO, 2018, p. 123-124)

Considerando tudo isso, o curso $\mathrm{MBI}$ em confecção 4.0 não poderia ter um formato diferente, apresentando soluções para educação à distância que agreguem tecnologias e metodologias atuais com valores para a construção colaborativa do conhecimento.

EaD supõe relação, interação e conectividade. Isso porque ensinar não é simplesmente repassar informações, além do que o aluno não é apenas um mero receptáculo de ideias; para que a aprendizagem ocorra, é preciso uma adaptação e uma reconstrução das informações recebidas. A comparação e a articulação dos novos conhecimentos com aqueles já consolidados exigem um diálogo constante entre o professor e os alunos, assim como também entre os alunos. 
Assim, o referencial teórico desse artigo permite avaliar o curso não só sob a ótica da EaD, mas de modo interdisciplinar da Sociologia da Educação e das Tecnologias Ubíquas temáticas da Indústria 4.0 (Automação, robótica, computação em nuvem, lot, Big Data, entre outras)

\section{PROCEDIMENTOS METODOLÓGICOS}

Para este trabalho foram realizadas entrevistas com questões abertas com gestores de conteúdo e participantes do $\mathrm{MBI}$ a fim de identificar pontos fortes e fracos na construção de um método diferenciado de ensino-aprendizagem. As entrevistas foram gravadas e tratadas por recorrência de palavras-chaves e conceitos essenciais para entendimento do curso analisado.

Além disso, recorreu-se à revisão bibliográfica de documentos importantes para o tratamento temático da formação Master Business Innovation em questão, bem como literaturas de referência para as Metodologias PBL e SENAI de Educação Profissional.

\section{APRESENTAÇÃO E DISCUSSÃO DOS RESULTADOS}

Conforme entrevista dada pelo Gestor de conteúdo e Gerente de Educação do SENAI CETIQT, Robson Wanka, a dinâmica esperada para a realização do curso é composta por sete passos para uma chamada Aprendizagem Ativa, sejam eles: Construção de projetos, Problematização, Aprendizagem significativa, Colaboração, Formação por competência, Aplicação prática e Imersão.

A partir desses elementos, foram planejados eixos temáticos que funcionam como um efeito mola (tensão e elasticidade), onde um tema se liga ao seu antecessor produzindo questionamentos para o sucessor. Esses elementos são melhor entendidos pelos alunos quando se tem uma perspectiva de convergências e divergências sobre os temas baseando-se em perguntas-chaves dentro de um projeto: O que é? Para que serve? Como se aplica? Quais as vantagens? Quais as desvantagens? 
Veja o exemplo no quadro abaixo:

\begin{tabular}{|c|c|c|c|}
\hline Eixo & Tema & Key words & Links com o sucessor \\
\hline 01 & $\begin{array}{l}\text { Estratégias de Inovação } \\
\text { posicionamento de negócios }\end{array}$ & $\begin{array}{l}\text { eDesign de negócios } \\
\text { Mercado; Valor }\end{array}$ & Definição de produto \\
\hline 02 & Materiais e Produtos & $\begin{array}{l}\text { Inovação; } \\
\text { Demanda }\end{array}$ & $\begin{array}{l}\text {;Aplicação } \\
\text { processos }\end{array}$ \\
\hline 03 & Processos Produtivos & $\begin{array}{l}\text { Sistemas; } \\
\text { Eficiência }\end{array}$ & $\begin{array}{l}\text { TICs; Robotização; } \\
\text { Automação }\end{array}$ \\
\hline 04 & Confecção 4.0 & $\begin{array}{l}\text { Tecnologias Ubíquas } \\
\text { Gestão; Viabilidade }\end{array}$ & $\begin{array}{l}\text { Investimento; Política } \\
\text { industrial }\end{array}$ \\
\hline 05 & Projeto e Análise de Viabilidade & Análise; Novos negócios & Novos consumidores \\
\hline
\end{tabular}

Quadro 1 - Relação temática do curso MBI Confecção 4.0

Destaca-se a realização dos momentos de imersão que favoreceram o relacionamento entre os participantes no desenvolvimento de projetos centrados no trabalho grupal. Além disso, as imersões, trouxeram um pouco de sala de aula invertida quando da realização das discussões previamente tratadas a partir de pílulas de conhecimento oferecidas e mediadas no Ambiente Virtual de Aprendizagem.

A experimentação metodológica abordou conceitos de estratégias e ações, que conforme RAZZERA (2018) são tendências para 2018, mas ainda assim ao longo das etapas vivenciadas pelos participantes, alguns ajustes foram sendo realizados a fim de melhor se adequar a realidade desses e das possibilidades de aprendizado de temas complexos, os quais nem sempre os participantes tinham familiaridade.

Em entrevista com participante do $\mathrm{MBI}$, verificou-se que os vídeos com duração maior que 10 minutos não tiveram boa aceitação, dado que a atenção era dispersada e o conhecimento passava muitas vezes a ser negligenciado, pois as informações organizadas e trabalhadas em outras mídias tornara-se mais realizável para 0 entrevistado. Dessa forma, aplicativos de comunicação instantânea como o WhatsApp ${ }^{\odot}$ ganharam, por vezes, maior relevância do que o Ambiente virtual de Aprendizagem do curso. Isso também abriu a leitura do participante para comentários sobre a tutoria, sua forma e importância que, foi declarada com importância mediana, se comparada às discussões feitas de maneira autônoma pelos demais participantes em uma espécie de contrato de networking.

Um ponto comum nas entrevistas do Gerente de Educação e do participante, foi em 
relação ao momento de imersão que garantiu uma integração entre os participantes. O trabalho feito nesse sentido, mostrou um desafio comumente encontrado na avaliação de cursos à distância quando da observação de competências de gestão (SENAI, 2013 p. 53), nesse caso, tratando de ética e relações interpessoais.

Questionado sobre a concorrência entre as empresas participantes acerca de estratégias de mercado sendo compartilhadas, Wanka afirma que "quando todos chegaram na primeira aula, todos ficaram na defensiva, mas conforme foram convivendo foram adquirindo confiança.". A consciência de classe praticada nesse tipo de atividade culminou em uma articulação empresarial intitulada Movimento Organizado Brasileiro do Setor Têxtil e de Confecção em prol da implantação da indústria 4.0. Evidencia-se o caráter formador de opinião gerado nesse grupo que ainda segundo Wanka é composto por empresas âncora e associam-se em função de implantações reais da confecção 4.0 no Brasil. "O MBI é um chamariz para reunir grandes empresas"

$\mathrm{Na}$ visão institucional do SENAI CETIQT, definida a estratégia com forte apelo às políticas educacionais e com currículo voltados as necessidades mais assertivas da indústria sob a perspectiva da Indústria 4.0, a formação para o trabalhador não segue a mesma proposta e/ou mesmo métodos do $\mathrm{MBI}$, mas deve ser fundamentada em situações de aprendizagem com problematização e aprendizagem significativa. Essa projeção liga a Metodologia SENAI de formação por competências e ainda pretende-se ser revisitada para uma adequação para o público em geral. Entretanto, já se pode listar como resultados a criação do Programa de Fortalecimento do Têxtil e Confecção, que será ofertado em 6 módulos e dando escalabilidade no atendimento às micro, pequenas e médias empresas com potencial para novas tecnologias industriais.

\section{CONSIDERAÇÕES FINAIS}

$O$ atual status de desenvolvimento de competências dos participantes do $\mathrm{MBI}$ em Confecção 4.0 mostra a necessidades de correções quanto o uso de elementos de metodologias já aceitas de modo geral como a PBL e a Metodologia SENAI de Educação Profissional. Além disso, é notório posicionamento dos participantes na aceitação de tecnologias de comunicação como 0 mensageiro instantâneo WhatsApp ${ }^{\odot .}$ O modelo adotado nesse $\mathrm{MBI}$ revela uma experiência ímpar na formação articulada de demandas de uma área industrial específica e pode ser tratada como uma metodologia própria e setorizada (Indústria têxtil e de confecção).

Os princípios de articulação e interação são amplamente explorados na prática da Educação à distância, mas verifica-se que ainda que a modalidade seja essa, os 
encontros presenciais, favorecem ainda mais a troca de experiências e o networking proposto no curso.

O atual andamento do curso permite ainda avaliações de gestores e participantes que indicam uma tendência para o uso mais intensivo das ferramentas e do ambiente virtual, dada a elaboração do projeto final que, exigirá uma maior comunicação entre os participantes. Porém, os resultados quanto às proposta complementares já são realidade quando se tem a institucionalização de programas de fortalecimento e implementação a indústria 4.0 nos setores têxtil e de confecção.

\section{REFERÊNCIAS}

ARAUJO, Ronaldo Marcos de Lima; FRIGOTTO, Gaudêncio. Práticas pedagógicas e ensino integrado. Revista Educação em Questão, v. 52, n. 38, p. 61-80, 2015. Disponível em:

BRASIL, Lei n. 9.394, de 20d e dezembro de 1996. Estabelece as diretrizes e bases da educação nacional.

CARDOSO, Antônio e BURNHAM, Teresina. Construção colaborativa do conhecimento com objetos de aprendizagem em um ambiente virtual de aprendizagem. INFORMÁTICA NA EDUCAÇÃO: teoria \& prática Porto Alegre, v.10, n.1, jan./jun. 2007.

CONFEDERAÇÃO NACIONAL DAS INDÚSTRIAS. Desafios para a indústria 4.0 no Brasil. - Brasília: CNI, 2016.

GRABOWSKI, Gabriel; KUENZER, Acácia Zeneida. A produção do conhecimento no campo da Educação Profissional no regime de acumulação flexível. Holos, v. 6, p. 22- 32, 2016. Disponível em: .

NORTHERN ILLIONOIS UNIVERSITY. Problem-based Learning. Disponível em:

<https://www.niu.edu/facdev/_pdf/guide/strategies/problem_based_learning.pdf $>$ Acesso em 06/08/2018

RAZZERA, Aline. Microlearning e Pílulas do Conhecimento ainda serão tendências para o mercado de capacitação em 2018?. Disponível em $<$ http://www.mobiliza.com.br/microlearning-pilulas-do-conhecimento/ >Acesso em 
06/08/2018.

SENAI, Departamento Nacional. Metodologia SENAI de Educação Profissional. Brasília: SENAI/DN, 2013.

STANFORD UNIVERSITY. How to do PBL. Disponível em:

$<$ http://ldt.stanford.edu/ jeepark/jeepark+portfolio/PBL/howtodopbl.htm>. Acesso em 06/08/2018. 